\title{
DETERMINING COSTS AND BENEFITS OF AN ONLINE GRADUATE PROGRAM IN HEALTHCARE EDUCATION: PRELIMINARY FINDINGS
}

\author{
Joseph W. York, MS, MBA \\ Assistant to the Head \\ Department of Medical Education \\ University of Illinois at Chicago \\ College of Medicine \\ 808 South Wood Street \\ MC 591 \\ Chicago, Illinois 60612 \\ Telephone: $312-996-3590$ \\ Fax: 312-413-2048 \\ Email: Jyork@uic.edu
}

\begin{abstract}
The Master of Health Professions Education degree offered by the University of Illinois' College of Medicine recently added an online track to its traditional in class format. The objective is to make the course available to healthcare professionals who might not be able to attend classes at the University. An analysis of enrollments and costs of the program indicate that interest in the online format is strong, and even with large costs for faculty time to convert and develop the courses in an online format, the program is financially viable. We also discuss future inquiry into learning outcomes and other economic aspects of online instruction.
\end{abstract}

\section{KEYWORDS}

Development, Student needs, Faculty interest, Economic viability

\section{INTRODUCTION}

Online educational programs have proliferated in recent years, spurred by the growth of the World Wide Web and interest in reaching new markets for students. Institutions have recognized the potential of the asynchronous online learning mode to lower the cost of adding additional students to a course [1]. They can then attract a broader range of students by lowering their tuition and fee charges. The cost structure for a distance learning program, especially one that is Internet-based, can be much different than its onground counterpart [2]. Generally it has been found that Internet-based educational programs have much higher fixed costs and relatively lower variable (that is, per student) costs [1]. The high fixed costs reflect the investment in technology and training the faculty and staff. However, once these are in place, the costs can then be spread over a large number of participants. The incremental costs of adding students is very small, since most of the activity is asynchronous, and does not require the presence of faculty. These two characteristics, high initial cost and low variable cost, have important implications for the financial justification of an online program.

The department of Medical Education at the University of Illinois at Chicago College of Medicine initiated an online track for its Master of Health Professions Education degree in early 1999. This 
program is aimed at healthcare professionals who hold or are planning to assume educational leadership positions. As the new track has progressed through a nearly complete cycle of course offerings, information on the costs and benefits of developing and presenting an on line track for a specialized graduate degree is emerging. This paper describes the methodology used to estimate these costs and benefits, and reports on some preliminary results.

\section{DESCRIPTION OF THE PROGRAM}

The Master of Health Professions Education degree (MHPE) was established at the University of Illinois' College of Medicine in the 1960's to develop healthcare educators with solid knowledge and skills in educational leadership and management. Although the largest single category of MHPE student consists of physicians, other fields such as nursing, dentistry, occupational therapy, physical therapy, and healthcare administration are also well represented.

The MHPE students make up a diverse group. Currently approximately 100 students are enrolled at various stages in their degree work. Table 1 shows the current distribution of students in both the traditional, classroom based track as well as the new online track. Not indicated here is that the international students include 13 Brazilians who participate in a special locally presented program sponsored by the Kellogg Foundation.

Table 1. Geographic and program distribution of MHPE students

as of Spring Semester, 2000

\begin{tabular}{|l|c|c|c|c|c|}
\hline Program & $\begin{array}{c}\text { Illinois } \\
\text { residents }\end{array}$ & $\begin{array}{c}\text { Other U.S } \\
\text { residents }\end{array}$ & Canadians & $\begin{array}{c}\text { Other } \\
\text { International }\end{array}$ & Total \\
\hline Traditional & 25 & 16 & 21 & 26 & 88 \\
Online & 4 & 5 & 1 & 0 & 10 \\
Total & 29 & 21 & 22 & 26 & 98 \\
\hline
\end{tabular}

Coursework for the MHPE includes four "block" courses, or required foundational courses that include topics such as instruction, assessment, curriculum design, program evaluation, and leadership. In addition, students take a number of electives as well as complete a thesis in order to graduate. These courses were offered in the past as either semester long evening courses or "intensives" with a semester's worth of instruction presented over the course of one to two weeks of eight-hour days.

In 1997, a group of MHPE faculty began to explore the possibility of presenting the MHPE program in an online format. The objective would be to reach those students, domestic or international, who could not participate in the program due to travel or personal constraints. At the same time, it was agreed that the course content and requirements for the online program would match those of the on-ground program to the greatest degree possible. The online courses would replace the semester-long weekly classes. While enrollment might be allowed to grow modestly, it was decided to restrict class size and courses offered to maintain the program's quality and individualized attention to students. The four block courses would be rotated in pairs, with two offered each year online, and the other two in traditional in class format. In opposite years, the two pairs of courses would switch formats. Electives would also be rotated, although some would remain online and others on ground at the discretion of the faculty.

To ease the transition to the online format, faculty are given the option of using instructional software provided by the institution's Instructional Technology Laboratory. 


\section{FINDINGS}

\section{A. Course Development and Initial Enrollments}

The initial task for the program was the development of a home page that would provide information for prospective and current students, and act as a central portal to online courses. This site can be found at www.mhpe-online.org. The first online MHPE course, an elective in clinical decision making, was presented in the Spring Semester 1999, with three students participating. The department presented two more electives that summer, and in Fall 1999 began offering its block courses. By Spring 2001, all block courses will have been offered online, as well as most of the electives.

During the first 16 months of the MHPE online program, student interest has been strong. The block courses have typically filled to capacity (15-20 students) with a waiting list. The electives, which tend to have smaller class sizes, have ranged from 1 to 10 students when offered online. This is similar to the inclass elective enrollment. The program policy is to allow students to have preferential registration within their own track. Students are then welcome to register for courses in the other track. Thus, although only 10 students have declared for the online track, the online enrollments have totaled over 105 to date for the 13 courses offered online, for a total of 304 credit hours earned online during this initial phase of the program. On an ongoing basis, it is anticipated that we will offer two blocks and eight electives online each year. Estimated student participation will be 88 enrollments for 256 credit hours earned.

\section{B. Identification of Costs}

The cost to develop and present a full Masters-level program online are estimated at approximately $\$ 120,150$ for the first 16 months. This includes the costs to develop twelve online courses (one elective has already been offered twice) to 105 enrollees. Table 2 displays the distribution of these costs. Following are explanations of how they were calculated.

Table 2. Incremental expenses for the MHPE online program development phase

\begin{tabular}{|c|c|c|}
\hline Description & Number of units & Total \\
\hline $\begin{array}{l}\text { Faculty Development } \\
(1 \text { month salary per } 4 \text { hour } \\
\text { course estimated at } \$ 6,000)\end{array}$ & $\begin{array}{l}\text { 3- } 4 \mathrm{hr} \text { courses } \\
\text { 9- } 2 \mathrm{hr} \text { courses }\end{array}$ & $\$ 56,250$ \\
\hline Technical staff (4 FTE's) & $1 / 3$ of total expense for Technical Core & $\$ 53,000$ \\
\hline Supplies & $1 / 3$ of total expense for Technical Core & $\$ 4,600$ \\
\hline $\begin{array}{l}\text { Computers, software, and } \\
\text { peripherals }\end{array}$ & $1 / 3$ of total expense for Technical Core & $\$ 4,000$ \\
\hline $\begin{array}{l}\text { Other services (telephone, } \\
\text { travel, maintenance) }\end{array}$ & $1 / 3$ of total expense for Technical Core & $\$ 2,300$ \\
\hline Total Expenses & & $\$ 120,150$ \\
\hline Per credit hour per student & 304 & $\$ 395$ \\
\hline
\end{tabular}




\section{Faculty}

The faculty are not compensated separately for developing courses or teaching online, so a direct measure of their cost cannot be made. However, we have estimated that a block course of four credit hours requires one month of faculty time to convert to the online format, and a two-hour elective takes half a month. At a median annual salary of $\$ 75,000$, plus $20 \%$ benefits, the development cost per course would be $\$ 7,500$. If more than one faculty member is involved with a course, it is assumed that the time would be distributed among those faculty. Faculty teaching time is not included as a cost because their teaching commitment is included in their base pay.

\section{Technical support}

After faculty development time, providing the infrastructure and support for the online effort is the largest cost for the MHPE program Instructional software and network servers are provided to departments by the campus, and their expense is not passed along to departments. This lowers the apparent cost of developing an online program, although the cost to the institution is substantial. On a department level, the MHPE program receives support from a "technical core" that includes a webmaster, project coordinator, graduate assistants, and equipment. Because the department sponsors three separate online programs, technical support for MHPE is estimated at one-third the total cost of the core.

\section{E. Other expenses}

Other expenses represent typical supply and service items needed by a unit such as the technical core. Included with the service expense is a toll-free telephone number that students can use if they encounter difficulties with logging on or navigating the online course.

Table 2 also shows the cost per enrolled credit hour (the number of students enrolled by course $\mathrm{X}$ the number of credit hours for each course) for this initial period of $\$ 395$.

\section{F. Ongoing Costs}

The above analysis showed a large cost per student as the enrollments absorbed the high cost of developing the program. On an ongoing basis, especially as faculty present courses for the second time, the actual costs will be much lower. One assumption made here is that faculty development time will be minimal, although we might expect some revising to take place as faculty become more inventive using online presentation tools, and new capabilities become available for presenting courses. New courses will of course require additional expense to develop, but these will also amortize their development costs over multiple presentation.

Additionally, although the technical support will remain, the equipment and software costs will be lower (but not zero; the short life span of PC's means that new units will need to be rotated in on a regular basis). Table 3 shows the estimate for a typical 12-month cycle of courses, with 2 4-hour block courses and 8 2-hour electives. On an ongoing basis, per credit hour costs drop to $\$ 192$ from $\$ 395$, representing in large part the decrease in faculty course development time. 
Table 3. Estimated ongoing costs for presenting the online MHPE program

\begin{tabular}{|c|c|c|}
\hline Description & Number of units & Total \\
\hline Technical staff (4 FTE's) & $\begin{array}{l}1 / 3 \text { of total expense for } \\
\text { Technical Core }\end{array}$ & $\$ 41,000$ \\
\hline Supplies & $\begin{array}{l}1 / 3 \text { of total expense for } \\
\text { Technical Core }\end{array}$ & $\$ 3,450$ \\
\hline Computers, software, and peripherals & $\begin{array}{l}1 / 3 \text { of total expense for } \\
\text { Technical Core }\end{array}$ & $\$ 3,000$ \\
\hline Other services (telephone, travel, maintenance) & $\begin{array}{l}1 / 3 \text { of total expense for } \\
\text { Technical Core }\end{array}$ & $\$ 1,800$ \\
\hline Total Expenses & & $\$ 49,250$ \\
\hline Per credit hour per student & 256 & $\$ 192$ \\
\hline
\end{tabular}

Student difficulties with the technology of online education appear to be manageable. Our technical core staff report that few students contact them for assistance, either via the toll free telephone line or an email listserv. Surveys performed in one of our other online programs indicate that most participants are able to get into the courses without our assistance, relying instead on instructions and "Frequently Asked Questions" posted on our web site.

\section{DISCUSSION}

The primary mission of the MHPE program is to provide a high quality education to current and future healthcare education leaders. Outreach is an important aspect of this mission, as a substantial portion of MHPE students are internationally based. The demographics of the initial enrollment of online students appear to parallel our traditional enrollment. A number of Chicago-based students have opted for the online track, suggesting that the appeal of the online program is broader than just overcoming geographic barriers. "Anytime-anywhere" course participation through an Internet-based program may be attractive to local students who find it difficult to balance a busy work schedule with regular class attendance. Students are also able to access the courses without undue difficulty. This observation may speak to the easy of use of the software we are using, or may indicate a self-selection for online courses by those students most comfortable with the technology.

The overall response to the online program has been strong, with over 100 enrollments in the first six semesters. While we have not yet compiled responses from students as to why they enrolled in an online course, many appear to be taking advantage of the opportunity to complete the program more quickly than they might if only the classroom tracks were available. This is especially true for the students who live outside of Chicago, although as noted above, substantial numbers of "in-town" individuals have also participated in the online courses.

Development of an online track for an established Master's program has required a substantial amount of resources. As predicted by various authors (e.g. Jewett, 1999), we experienced a large one-time expense for program development that will be spread over a large number of students over time. While the percredit hour expense is initially large, it is expected to drop substantially once the development and conversion of online courses is largely completed. The expense estimates presented here compare favorably with tuition charges. UIC tuition is charged on a range basis, so a per-credit hour charge must 
be estimated. Non-resident tuition per hour is approximately $\$ 460$; in state residents pay about $\$ 163$. With a mix of 2:1 for non-resident versus in-state students, the ongoing cost of $\$ 192$ appears to be viable if tuition revenues are to cover program costs. One caveat should be mentioned; institutional support for the online programs is substantial, and has not been estimated here. On a school-wide basis, a portion of the tuition should be allocated for the technical support provided by central labs and offices to the online MHPE program.

One prescription for creating a cost-effective distance education program is to increase enrollments, taking advantage of the economies of scale inherent in online education [1]. The MHPE program is designed to provide its professional student clientele with a high quality, individualized curriculum. Participants value the interaction (online or live) with faculty, and the courses deal with complex organizational issues. For all of these reasons, the program is not expected to expand dramatically beyond its current volume of students. Therefore, the marketing emphasis has been directed to informing the medical education community that an online track is now available. This is being accomplished through mailings to chief education officers at medical schools and teaching hospitals. We also rely on our current and former students to identify candidates and refer them to the MHPE program. Over time, marketing will emphasize the quality of the online experience and the attractiveness of the format for those who cannot or prefer not to travel to take our courses.

Finally, the early success of the program has led to discussions as to how the online format might be utilized to meet other department objectives. The Department of Medical Education has over the years presented the MHPE program at distant sites, such as China, Egypt, and most recently Brazil, often with outside support. As future special projects are discussed, the possibility of providing a portion of the instruction online is being considered, to lower the cost of faculty travel and per diem to these distant sites. The substantial cost savings realized by eliminating these costs could be used to bring the technology at the foreign site up to standards for its students, and would provide benefits beyond accessing the MHPE program.

\section{ISSUES FOR FURTHER STUDY}

The MHPE online program is in its initial phase and evaluation of its impact on students and faculty is still being developed. So far, no evidence indicates that drop out rates for the online program differ from those of the semester long in class courses of the past. Anecdotally, faculty have reported substantial investment in time and effort to learn the new online teaching software, and to convert their classes. Presumably, once the core of courses is completed, and the learning curve scaled, the demand on faculty time will abate.

Outcome measures for the online courses as compared to their more traditional counterparts need to be estimated. The potential to contribute to our understanding of the dynamics of online learning is great, because the program set as one of its goals to keep the course content as similar as possible between the in class and online formats. How to measure outcomes in courses that are qualitative, such as leadership, is a challenge that our faculty are debating.

Another aspect of the economics of distance education that is not reported in great depth is that of the costs and benefits to students. Yet, the success of online educational programs hinge on students making a decision that the online format is the most cost-effective means of completing coursework. Equipment costs, access, and learning how to use the technology are traded off against the cost of travel to the course presentation site, on a regular schedule. It is intuitive that students self-select a format based on individual costs and benefits, and comfort with technology. In the case of MHPE, we would predict that since most 
students are healthcare professionals, their tradeoff is one of time lost from the job or personal life if they attend classroom instruction. In general, they seem comfortable with the technology, based on the low frequency of help requests, as well as student retention. It would be useful to poll students to identify which factors attracted them to the online format, as well as what their costs are compared to taking a traditional course on site.

\section{CONCLUSIONS}

The addition of an online format to a long standing, specialized graduate program appears in its early stages to be successful. Enrollments are strong, even for students who presumably could attend classes at our Chicago site. A financial analysis of the program demonstrates that it is financially viable on an ongoing basis. Even for a program that is not seeking to maximize the economic strength of the online format by increasing its enrollment, the MHPE program benefits from an online track by providing the curriculum to students who might otherwise not attend traditional classes.

\section{ACKNOWLEDGMENTS}

Funding for development of the Master of Health Professions Education (MHPE) Online program at the University of Illinois at Chicago College of Medicine was provided by a grant from the UI Online Initiative. The activities described in this paper represent the hard work of members of the MHPE Online Committee of the Department of Medical Education, and their contributions to the success of the project are duly acknowledged, especially those of Annette Yonke, PhD, who has served as chair of the MHPE Online Committee and project director.

\section{REFERENCES}

1. Jewett, F. A framework for the comparative analysis of the costs of classroom instruction vis-à-vis distributed instruction. 1999. [Online] http://academic.shu.edu/itcosts/jewett.pdf .

2. Rumble, G. The costs and economics of open and distance learning. Stirling, VA: Kogan Page, 1997.

\section{ABOUT THE AUTHOR}

Joseph W. York, MS, MBA is Assistant to the Head of the Department of Medical Education at the University of Illinois at Chicago College of Medicine.

Address: 808 South Wood Street, MC 591, Chicago, Illinois, 60612; telephone: 312-996-3590; fax: $312-$ 413-2048; email: Jyork@uic.edu. 